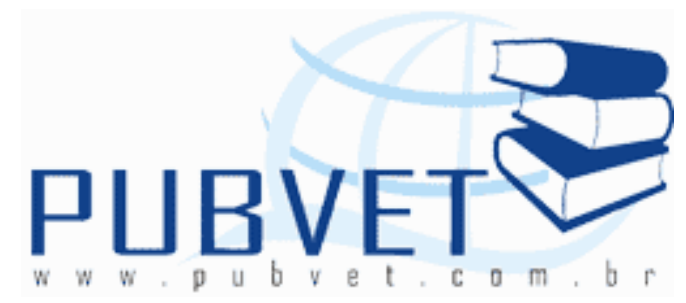

PUBVET, Publicações em Medicina Veterinária e Zootecnia.

Disponível em: <https://doi.org/10.31533/pubvet.v02n12a477.1-14>.

\title{
Técnicas de colheita de sangue em suínos
}

Francisco Rafael Martins Sotoa, Silvio Arruda Vasconcellos ${ }^{b}$, Sônia Regina Pinheiro $^{b}$, Fernanda Bernardia, Erlete Rosalina Vuadenc, Fumio Honma Itob

aCentro de Vigilância Sanitária e Controle de Zoonoses "Tereza Rodrigues de Camargo", Estrada da Vargem do Salto- Km 4,5- Bairro dos Paes - Ibiúna SP, Brasil, CEP18150-000

bDepartamento de Medicina Veterinária Preventiva e Saúde Animal, Faculdade de Medicina Veterinária e Zootecnia, Universidade de São Paulo, Avenida Prof. Dr. Orlando Marques de Paiva, 87, Cidade Universitária, CEP 05508-900, São Paulo, SP, Brasil

c M Cassab Departamento de Nutrição Animal- Avenida das Nações Unidas, 20882 CEP 04795-000- São Paulo, SP , Brasil

Resumo: Este artigo detalha com técnicas de colheita de sangue em suínos para testes sorológicos, com comentários e fotografias ilustrativas.

Palavras chave: suínos; técnicas; colheita de sangue 


\section{Bleeding techniques in swine}

Abstract: This paper deals with bleeding techniques in swines for serologic testings, with comments and photographic illustrations.

Key words: swines; techniques; bleeding

\section{Introdução}

A sorologia em suínos é um procedimento importante para o diagnóstico de doenças ou infecções, causadas por microorganismos tais como Leptospira, Brucella, Toxoplasma, Mycoplasma, Parvovírus e Herpes vírus (SOBESTIANSKY et al.; 1999).

Na Faculdade de Medicina Veterinária e Zootecnia da Universidade de São Paulo (FMVZ/ USP), há mais de 25 anos, as técnicas aqui apresentadas vem sendo aplicadas em aulas práticas do curso de graduação em medicina veterinária e as experiências adquiridas são aqui apresentadas com documentação fotográfica. Apesar da relevância do tema, poucos são os artigos técnicos disponíveis sobre colheita de sangue em suínos, o que motivou os autores a escrevê-lo.

Este trabalho teve por objetivo descrever detalhadamente técnicas de colheita de sangue em suínos para testes sorológicos e experimentos científicos.

\section{Descrição das técnicas}

Foram utilizados suínos híbridos das raças Large White, Landrace e Duroc, criados em uma granja comercial, localizada no Município de Ibiúna - SP, com um plantel de 170 matrizes. Para a colheita de sangue, foram utilizados animais recém-nascidos ou até uma semana de idade, leitões desmamados e reprodutoras a partir de 230 dias.

Foram utilizadas seringas plásticas descartáveis da marca Becton Dickinson $®$ (B-D), com volume de $10 \mathrm{~mL}$ e agulha de calibre $0,7 \times 25 \mathrm{~mm}\left(22 \mathrm{G}^{1 \prime \prime}\right)$ para os leitões recém nascidos a uma semana de idade e desmamados. Com seringa e agulha de calibre $1,2 \times 40 \mathrm{~mm}\left(18 \mathrm{G} 1^{1 / 2 "}\right)$ para as matrizes suínas. Foi utilizado 
vacutainer com agulhas de calibre $0,9 \times 25 \mathrm{~mm}\left(20 \mathrm{G}^{1 \prime \prime}\right)$ e $0,7 \times 25 \mathrm{~mm}$ $\left(23 \mathrm{G}^{3 / 4^{\prime \prime}}\right)$ com capacidade para $10 \mathrm{~mL}$, marca $\mathrm{B}-\mathrm{D} \AA$. Dispositivo para infusão intravenosa, marca $B-D \circledast$, equipado com agulha de calibre $0,7 \times 25 \mathrm{~mm}$ $\left(23 G^{3 / 4 \prime}\right)$ para os leitões recém nascidos ou de até uma semana.

Foram utilizadas cinco técnicas: veia jugular, veia marginal da orelha, veia mamária, veia caudal e veia braquial.

As colheitas de sangue foram efetuadas com o emprego de seringas, vacutainers e equipo borboleta-assepto $23 \mathrm{G}$ marca $\mathrm{B}-\mathrm{D} \Omega$. O volume de sangue obtido para os animais adultos ou adultos jovens foi de oito a $10 \mathrm{~mL}$ e para os leitões recém nascidos ou até de uma semana foi de três a cinco mL.

A localização anatômica dos métodos utilizados nas colheitas de sangue são apresentadas nas Figuras de 1 a 12 com os respectivos comentários.

As amostras de sangue são mais comumente colhidas da veia jugular externa. O animal deve ser contido com uma corda ou cachimbo com corda de fio de nylon, com o pescoço distendido e cabeça levemente levantada (Figura 1b). Esta posição é alcançada quando o suíno permanece em estação, com apoio nas quatro patas. A corda é colocada atrás dos dentes caninos cuidando-se para que não deslize e venha a se soltar. O local correto para a punção é ilustrado na Figura 2b. A agulha deve ser direcionada caudo-dorsalmente, em posição perpendicular à pele.

A Figura 2c está mostrando a mesma matriz, com foto tirada de lado. O local da punção corresponde ao ponto mais profundo da fossa da jugular, formada entre os músculos esternocefálico medial e braquiocefálico lateral (POPESKO, 1983). Indivíduos destros normalmente acham mais confortável efetuar a colheita de sangue pela veia jugular do lado direito do animal.

A agulha do tubo vacutainer de calibre $0,7 \times 25 \mathrm{~mm}\left(23 \mathrm{G}^{3 / 4^{\prime \prime}}\right)$ com capacidade para $10 \mathrm{~mL}$, marca $\mathrm{B}-\mathrm{D} \circledast$ já conectado à agulha ou a agulha da seringa descartável são relativamente curtas para uma matriz ou marrã, portanto, nestes animais o tecido adiposo sobre a veia deve ser pressionado para que a agulha alcance a veia jugular. Pode-se ver o sangue fluindo para o tubo ou a seringa (Figuras $2 \mathrm{c}$ e $3 \mathrm{~b}$ ). 
A Figuras $2 \mathrm{~d}$ e $2 \mathrm{e}$ demonstram a mesma situação da apresentação anterior onde a foto foi tirada diagonalmente de frente. A fossa da jugular é facilmente percebida. É importante que o operador segure firmemente o adaptador, caso queira trocar de tubo vacutainer. A amostra de sangue está sendo obtida da veia jugular externa direita. O adaptador do tubo está sendo fixado a sua mão esquerda, e gentilmente pressionando-o contra o pescoço da matriz. Neste caso as trocas do tubos serão efetuadas com mão direita.

Figura 1-Contenção física de um suíno adulto, indicando o local de penetração da agulha, pela veia jugular (lado direito), com utilização de corda de nylon e cachimbo.

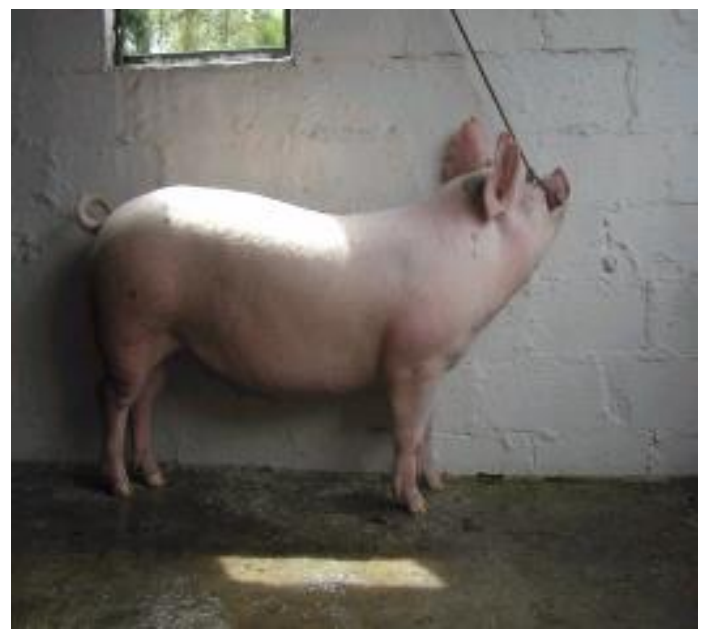

Figura1a

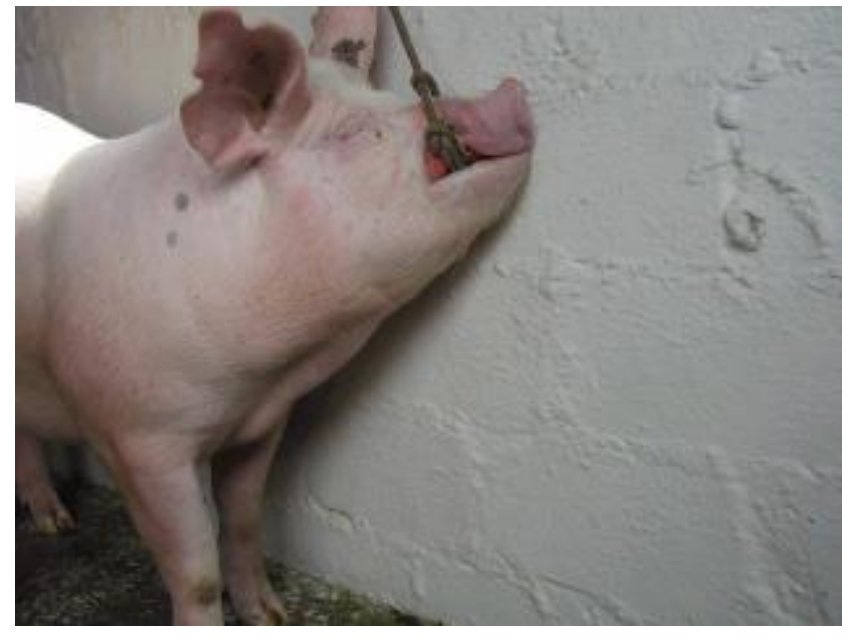

Figura1b 
Soto, F.R.M., Vasconsellos, S.A., Pinheiro, S.R. et al. Técnicas de colheita de sangue em suínos. PUBVET, Londrina, V. 2, N. 50 Art\#477, Dez3, 2008.

Figura 2-Contenção de um animal adulto jovem (Figura 2 a) com utilização de cachimbo e corda de nylon, indicando o local de penetração da agulha pela veia jugular (lado direito) (Figura 2 b), e a colheita de sangue efetuada ( Figura 2 c, Figura 2 d e Figura 2 e).

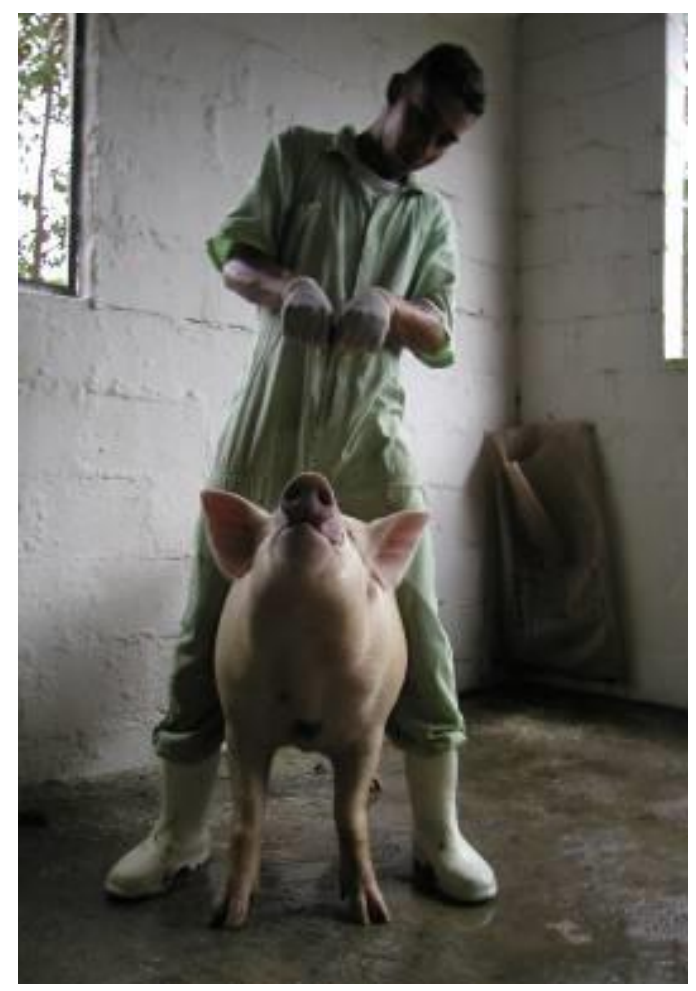

Figura 2 a

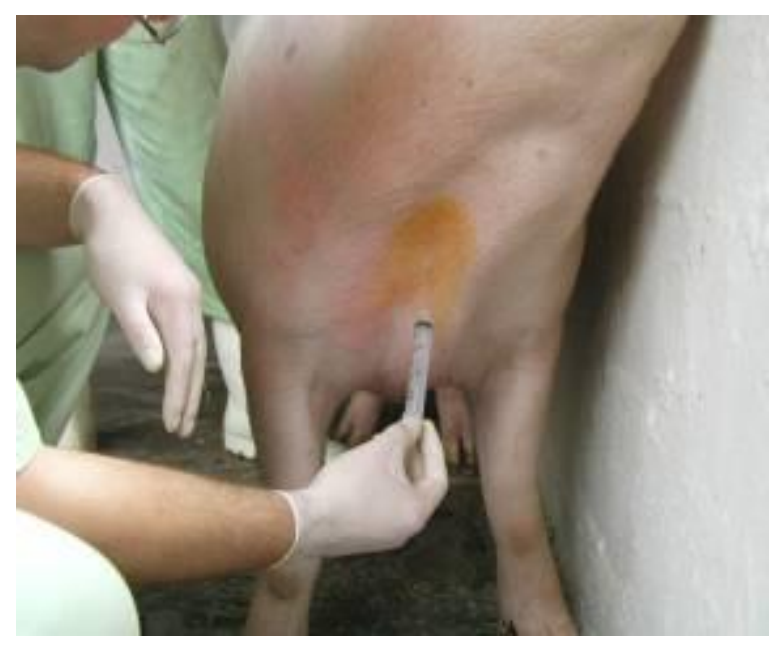

Figura $2 \mathrm{~b}$

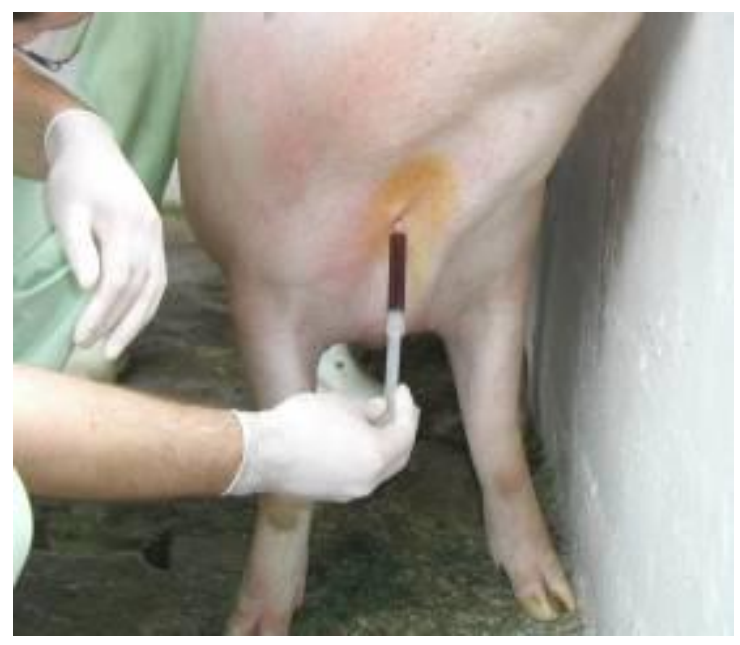

Figura $2 \mathrm{c}$ 


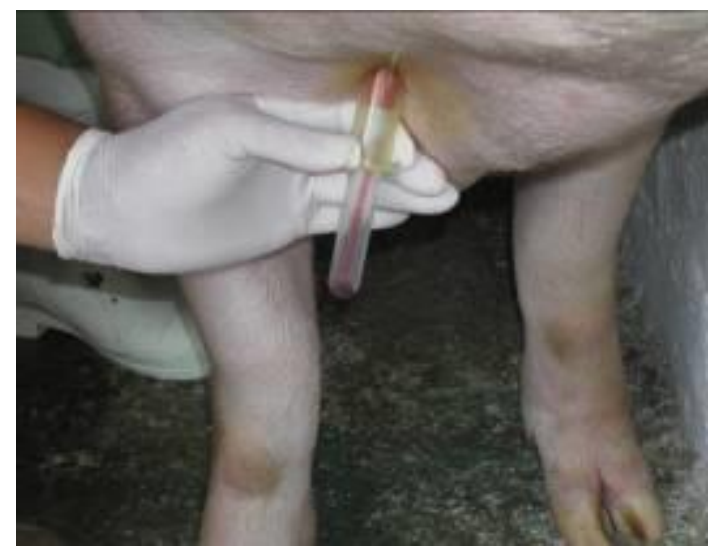

Figura $2 \mathrm{~d}$

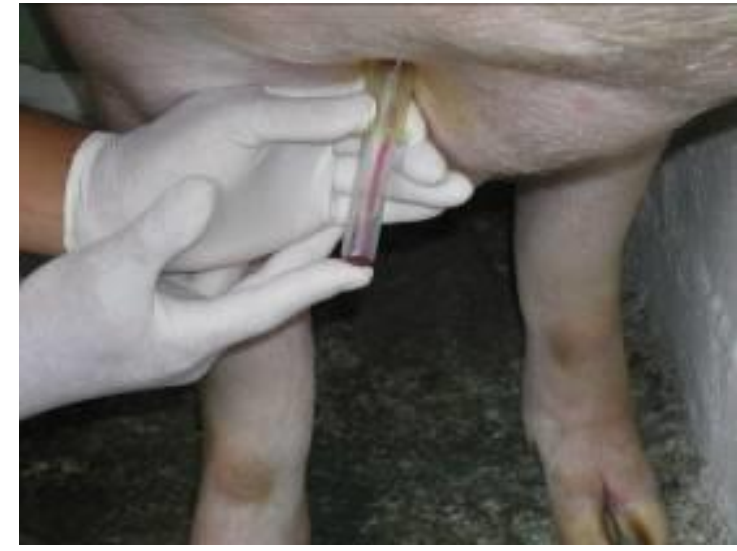

Figura 2 e

Em suínos com peso inferior a $50 \mathrm{~kg}$ é vantajoso colher sangue um pouco mais caudalmente (e mais medialmente) na fossa jugular, mais próxima ao manúbrio. Dependendo do local da punção, ângulo e profundidade da penetração, o sangue pode ser colhido da veia jugular ou da artéria carótida. 0 assistente pode segurar o animal de até $20 \mathrm{~kg}$ entre as pernas, fixando as duas patas dianteiras com uma das mãos, e a outra segurando a cabeça (Figura 4a).

Para leitões com peso inferior a $50 \mathrm{Kg}$ é conveniente o emprego de seringas e agulhas de calibre 0,7 × $25 \mathrm{~mm}$ ou $0,9 \times 25 \mathrm{~mm}$, já para suínos maiores, podem ser utilizadas agulhas de calibre $1,2 \times 40 \mathrm{~mm}$. Quando a agulha penetra a pele, o operador deve puxar o êmbolo lentamente, ao mesmo tempo que penetrando a seringa mais profundamente. Após penetrar 10-25 mm, dependendo do vaso puncionado, o sangue começa a fluir. Neste momento a seringa ou o tubo deve ser mantido na posição, até o término da colheita (Figura 3b).

As Figuras $4 b, 4 c$ e $4 d$ ilustram a colheita de sangue de um leitão recémnascido, fotografia tirada de lado. O leitão está contido entre as pernas do auxiliar, que fixa a cabeça e os membros anteriores. A cabeça não deve ficar muito distendida, pois há prejuízo do fluxo sangüíneo da região do pescoço. Para facilitar a colheita de sangue, a agulha pode ser conectada ao tubo plástico. 
Suínos entre 20 e $50 \mathrm{Kg}$ podem ser contidos com o uso de cachimbo. O manúbrio está marcado com a tinta azul (Figura 3 a).

Figura 3- Contenção física de um leitão desmamado, indicando o local de penetração da agulha, pela via jugular (lado direito) (Figura 3 a) e a colheita de sangue efetuada ( Figura 3b).

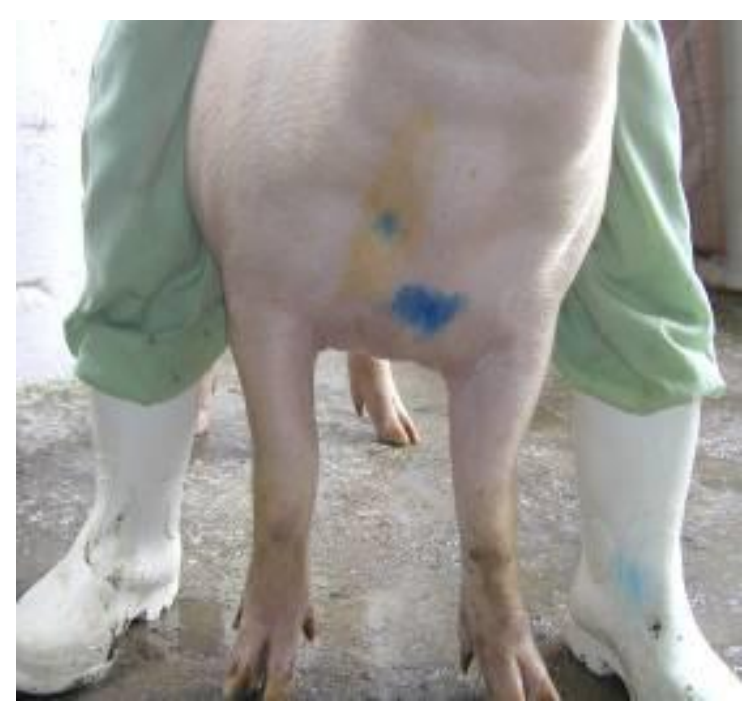

Figura 3 a

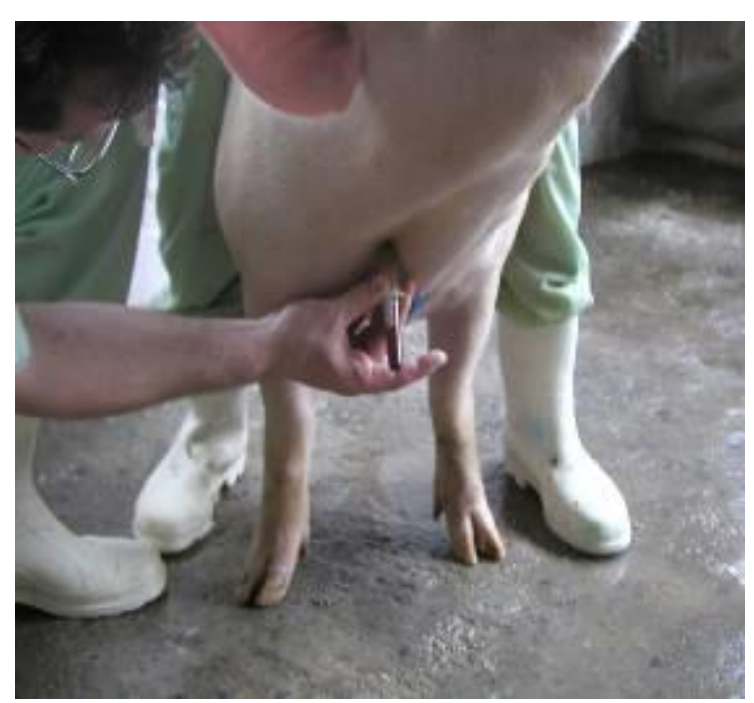

Figura 3 b

Figura 4-Contenção física de um leitão recém nascido indicando o local de penetração da agulha (foto $4 a$ ) e a colheita de sangue com equipo borboleta (foto $4 \mathrm{~b}$ ), seringa ( foto $4 \mathrm{c}$ ) e vacutainer (foto $4 \mathrm{~d}$ ), pela via jugular (lado direito)

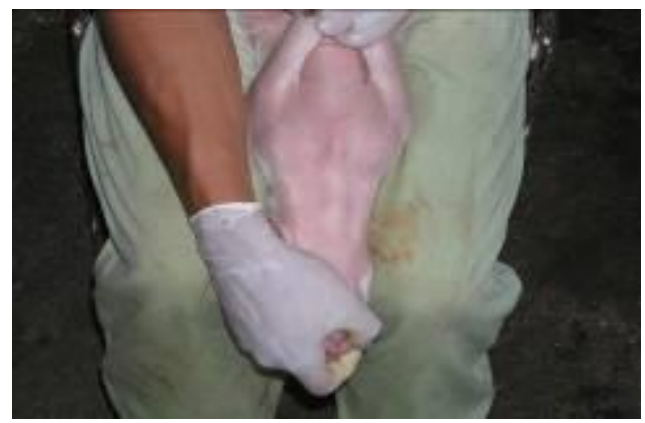

Figura 4 a 


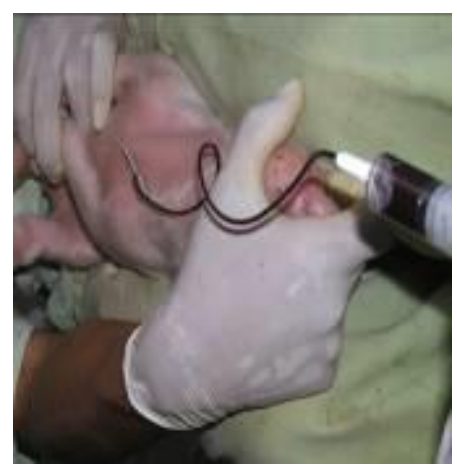

Figura $4 \mathrm{~b}$
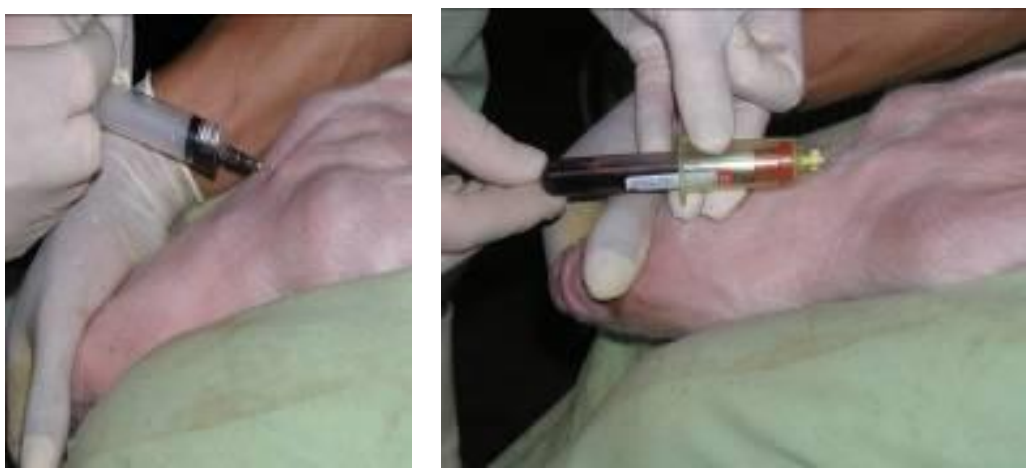

Figura $4 \mathrm{c}$
Figura $4 \mathrm{~d}$

As veias marginais da orelha são as únicas visíveis em suínos de várias idades (Figura 5). Há três veias proeminentes, a veia lateral ou a central que é a maior delas. As veias das orelhas são ramificações da veia auricular caudal e da veia cervical superficial (POPESKO, 1983). Na Figura 6, o auxiliar está bombeando a veia para facilitar o fluxo de sangue e na Figura 7 a colheita de sangue está sendo efetuada com a utilização de equipo tipo borboleta. Como os suínos não transpiram, a circulação sangüínea através da orelha é um mecanismo importante para a regulação térmica (POND; HOUPT, 1981). Em ambiente quente as veias se dilatam e a colheita de sangue é facilitada.

Figura 5-Veias marginas da orelha de suínos adultos

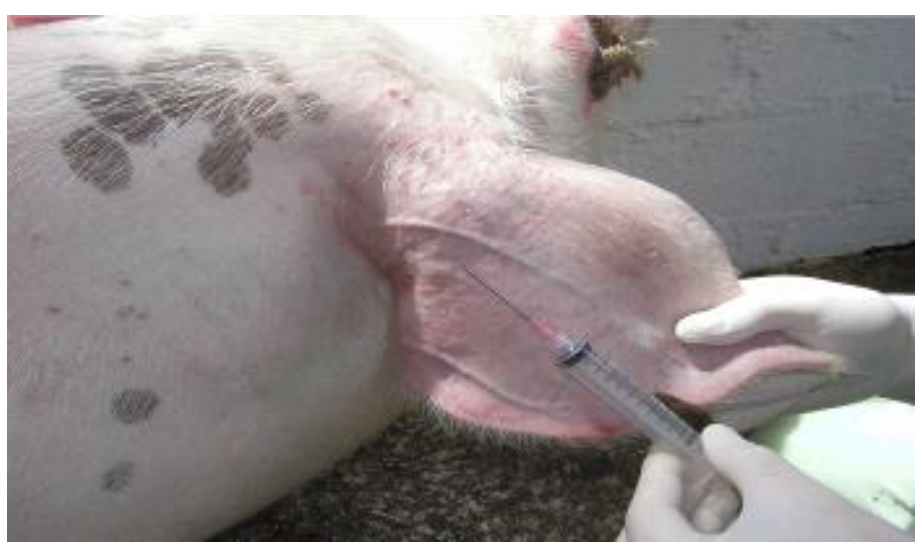


Figura 6- Auxiliar está bombeando a veia para facilitar o fluxo de sangue

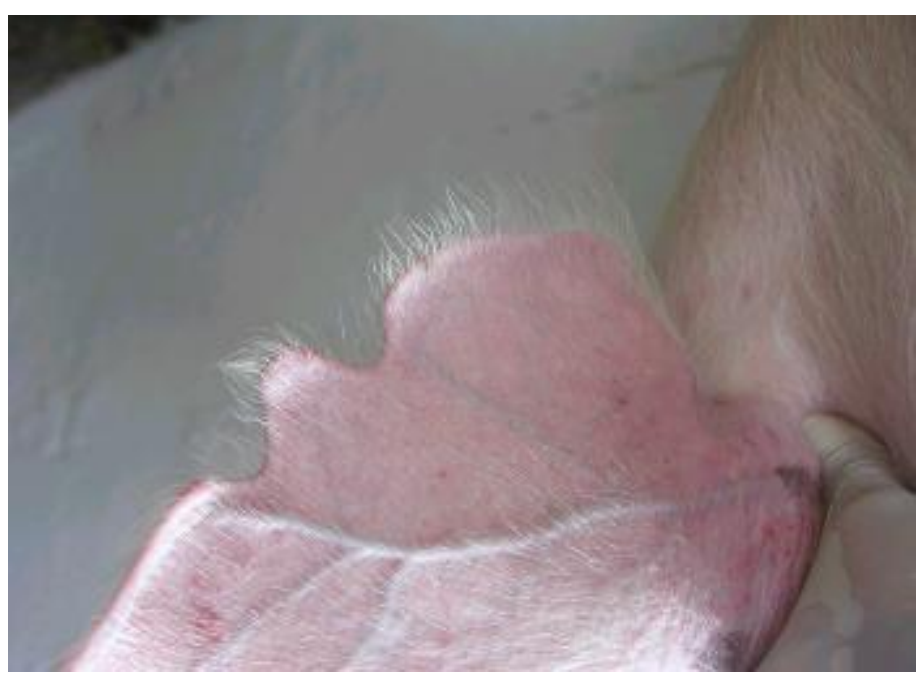

Figura 7- Colheita de sangue sendo efetuada com a utilização de equipo tipo borboleta

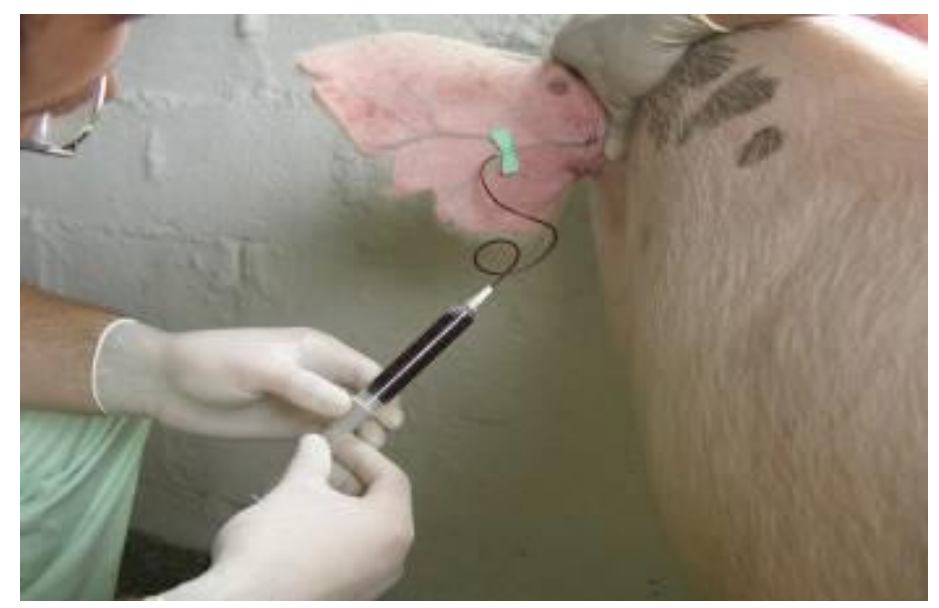

A veia mamária ou veia abdominal subcutânea é facilmente e visível lateralmente às tetas, em leitões menores (Figura 8a). O suíno da foto pesa aproximadamente $40 \mathrm{~kg}$. A veia localiza-se subcutaneamente na parte lateral da musculatura abdominal e é facilmente palpada entre as duas fendas musculares. Para a colheita de sangue, é utilizado um tubo à vácuo ou agulha de calibre $0,7 \times 25 \mathrm{~mm}$. A agulha é inserida no ponto onde a veia é mais visível. Na foto, a agulha foi inserida na direção cranial e lateralmente a segunda teta. 
Suínos pesando mais de $50 \mathrm{Kg}$ devem ser imobilizados com cachimbo ou corda (Figura 2a).Palpa-se a veia e a pele é perfurada no ponto onde a sensação da veia é mais evidente (CARLE; DEWHIRST, 1942). Conecta-se então o tubo de vácuo e a agulha é cuidadosamente movida em direção à veia até a sua perfuração. O operador permanece em pé no lado direito do animal e insere a agulha rostralmente. Esta posição normalmente é considerada a melhor para os operadores destros. No lado esquerdo do animal, usualmente será mais fácil a inserção da agulha caudalmente (HOERLEIN; HUBBARD; GETTY, 1951).

A veia é puncionada entre as glândulas mamárias. Este é o ponto onde a veia do leite é facilmente de ser palpada. A veia pode estar mascarada entre as glândulas de matrizes com úberes bem desenvolvidos. Em suínos de aproximadamente $40 \mathrm{~kg}$ ou mais, é possível colheita de volume de sangue suficiente que possibilite a realização de investigações sorológicas (Figura 8 b).

Figura 8- Veia mamária de um suíno jovem ( Figura 8 a) e a colheita de sangue efetuada com vacutainer ( Figura 8 b) .

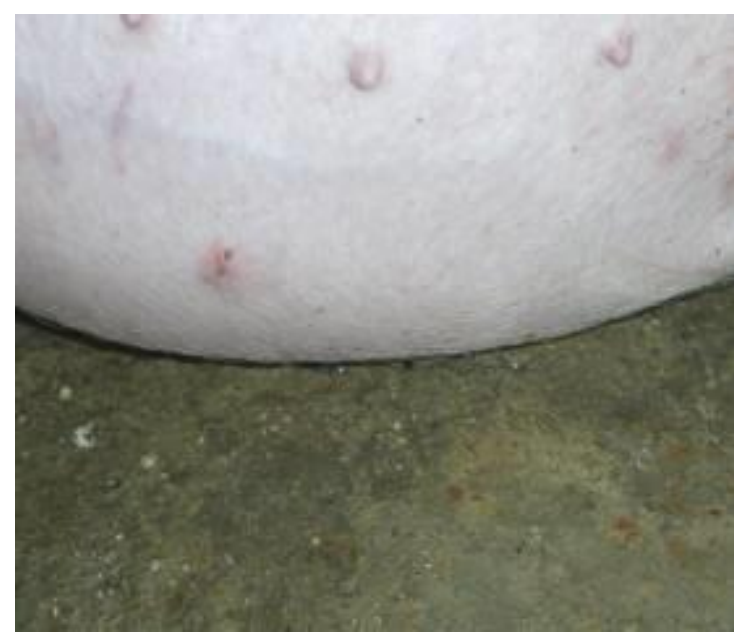

Figura 8 a

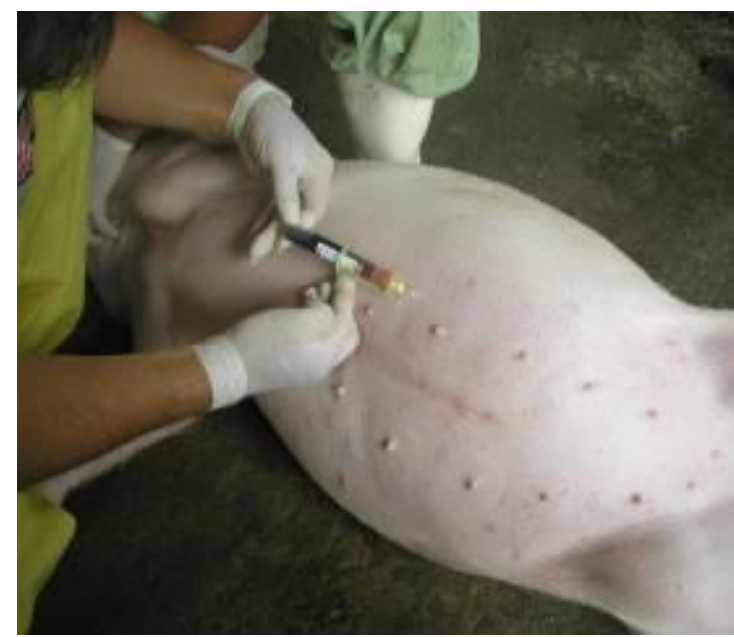

Figura $8 \mathrm{~b}$

A veia caudal medial está localizada na fossa sob a cauda, próxima à artéria (POPESKO, 1983). O operador levanta a cauda com uma das mãos e com a outra, punciona a veia. Utiliza-se para tanto, um vacutainer com agulha de calibre $0,7 \times 25 \mathrm{~mm}$ ou seringas com agulha de calibre $1,2 \times 40 \mathrm{~mm}$, como 
indicado na Figura 9. O local da punção é na primeira articulação móvel. Este ponto é próximo da $5^{\mathrm{a}}$. vértebra caudal. Em suínos adultos a agulha deve ser inserida num ângulo de $45^{\circ}$ à pele. Em suínos pequenos, recomenda-se segurar a cauda quase horizontalmente e inserir a agulha paralela à pele.

A Figura 10 ilustra a colheita de sangue da veia caudal medial. É difícil de obter sangue em grandes volumes por este método, mesmo em suínos de grande porte. A artéria localiza-se próxima à veia, e frequentemente é obtido o sangue arterial, porém, não oferece à qualquer risco para o animal.

Figura 9 Veia caudal e a localização da agulha para a colheita de sangue por esta via

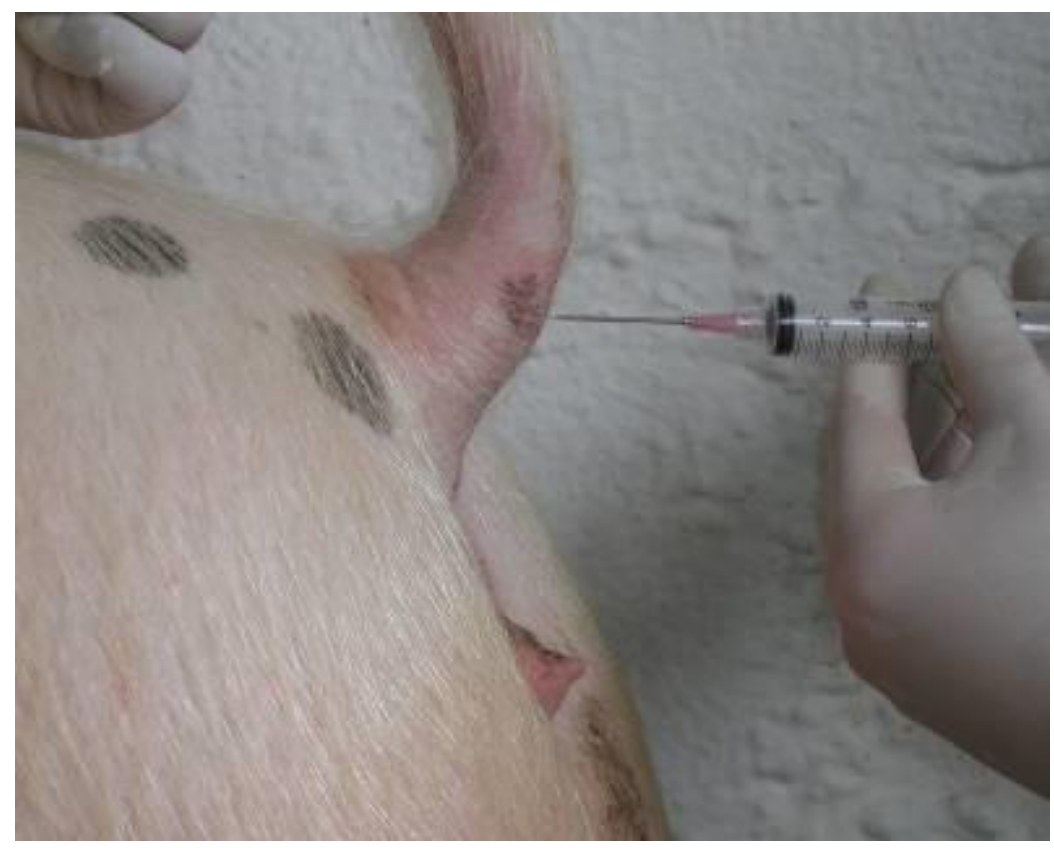


Figura10- Colheita de sangue sendo efetuada pela veia caudal.

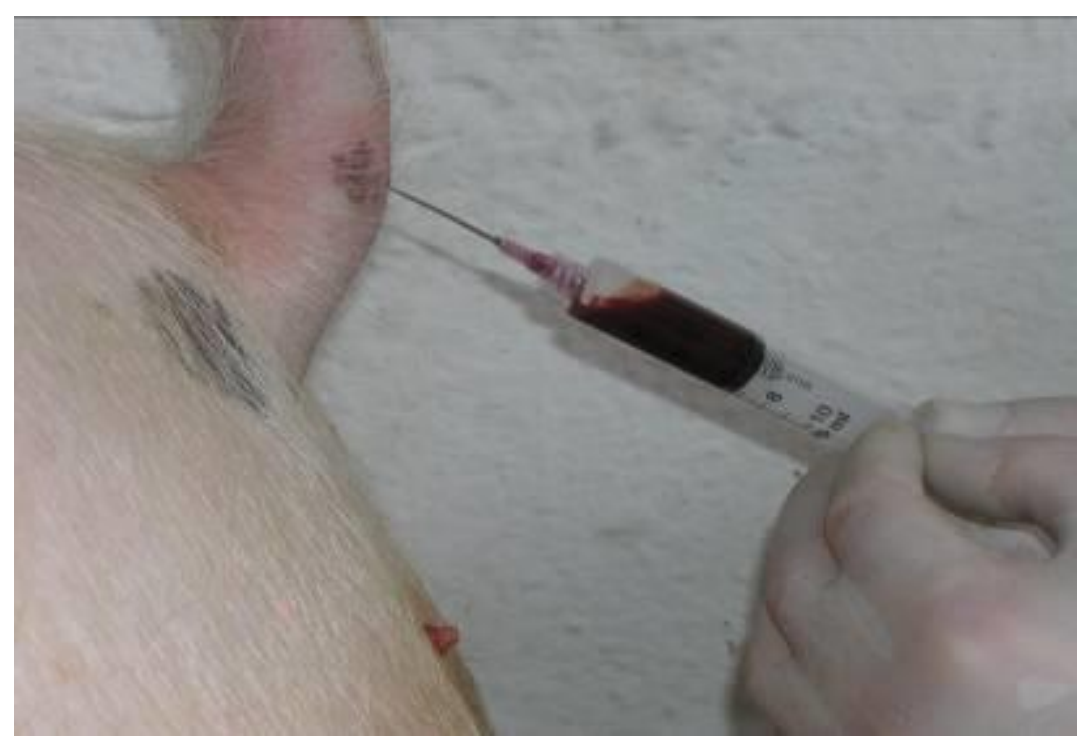

A veia braquial pode ser utilizada para colheita de sangue de leitões recémnascidos e animais desmamados, contudo, volume obtido é de $3-5 \mathrm{~mL}$ de sangue por esta via, com limitações (Figura 12). O animal deve ser deitado com o dorso voltado para baixo, e os membros posteriores distendidos. Os membros anteriores devem estar distendidos um pouco para trás e ligeiramente abertos lateralmente (Figura 11). Esta posição permite que a veia se distenda em linha reta e fique mais acessível a punção. A veia e o manúbrio estão demarcados com tinta azul.

Figura 11- Localização destacada com tinta azul da veia braquial de um suíno jovem

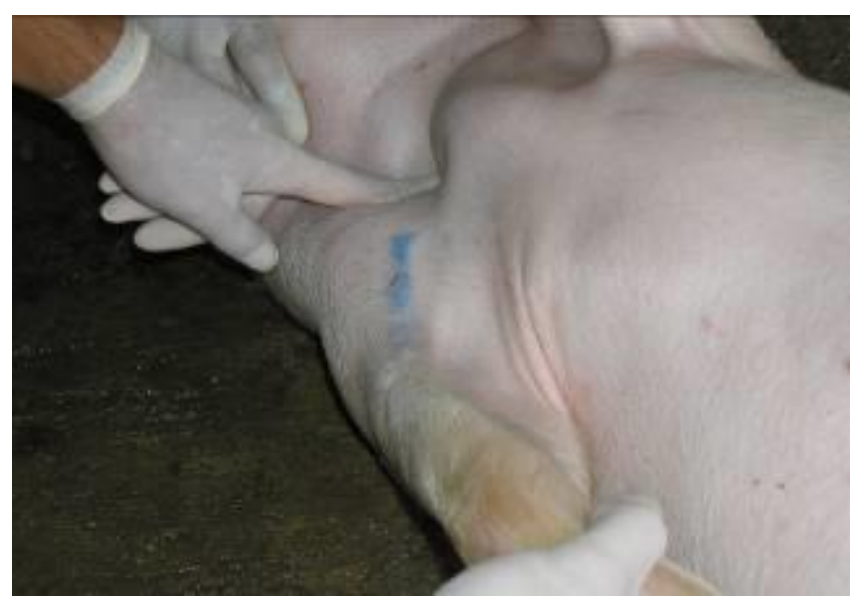


Figura 12- Colheita de sangue sendo efetuada pela veia braquial.

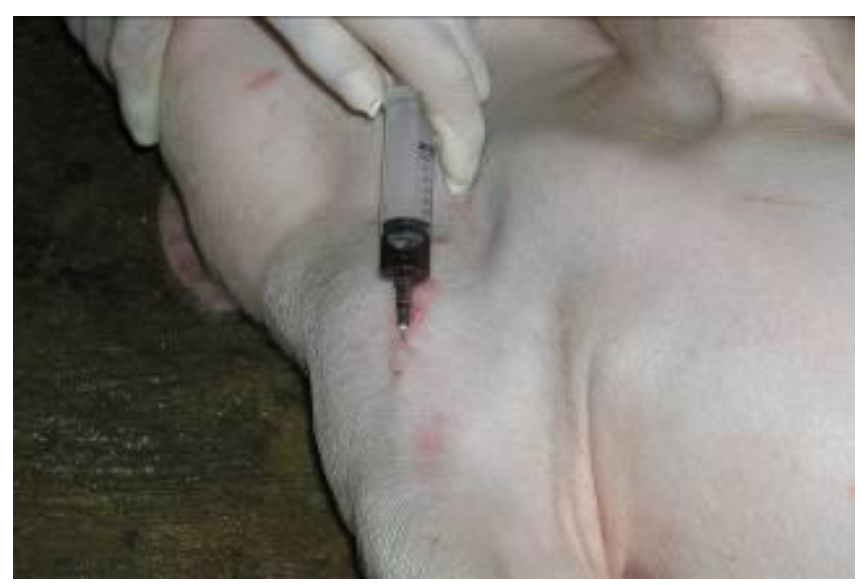

\section{Discussão e Conclusão}

As técnicas aqui descritas são utilizadas há mais de 25 anos na FMVZ-USP, sem ter ocorrido casos de acidentes fatais. A técnica é também aplicada nas pesquisas envolvendo inquéritos sorológicos, onde há a necessidade de colheita de sangue de animais de diferentes faixas etárias, e em condições de assepsia.

Com o uso de vacutainer ou seringas plásticas descartáveis com agulhas de diferentes calibres $(0,7 \times 25 \mathrm{~mm}$ e $1,2 \times 40 \mathrm{~mm})$, é possível a colheita de sangue de suínos de diferentes faixas etárias, com relativa facilidade, exigindo um mínimo de conhecimento anatômico desta espécie e em situações de assepsia satisfatórias. Em condições usuais de criação de suínos, o método de colheita pela veia jugular externa é o mais recomendado (FRAMSTAD; AASS, 1988). 
Figura 13- Sangue armazenado em tubos de vacutainer e de ensaio em volumes satisfatórios para inquéritos sorológicos

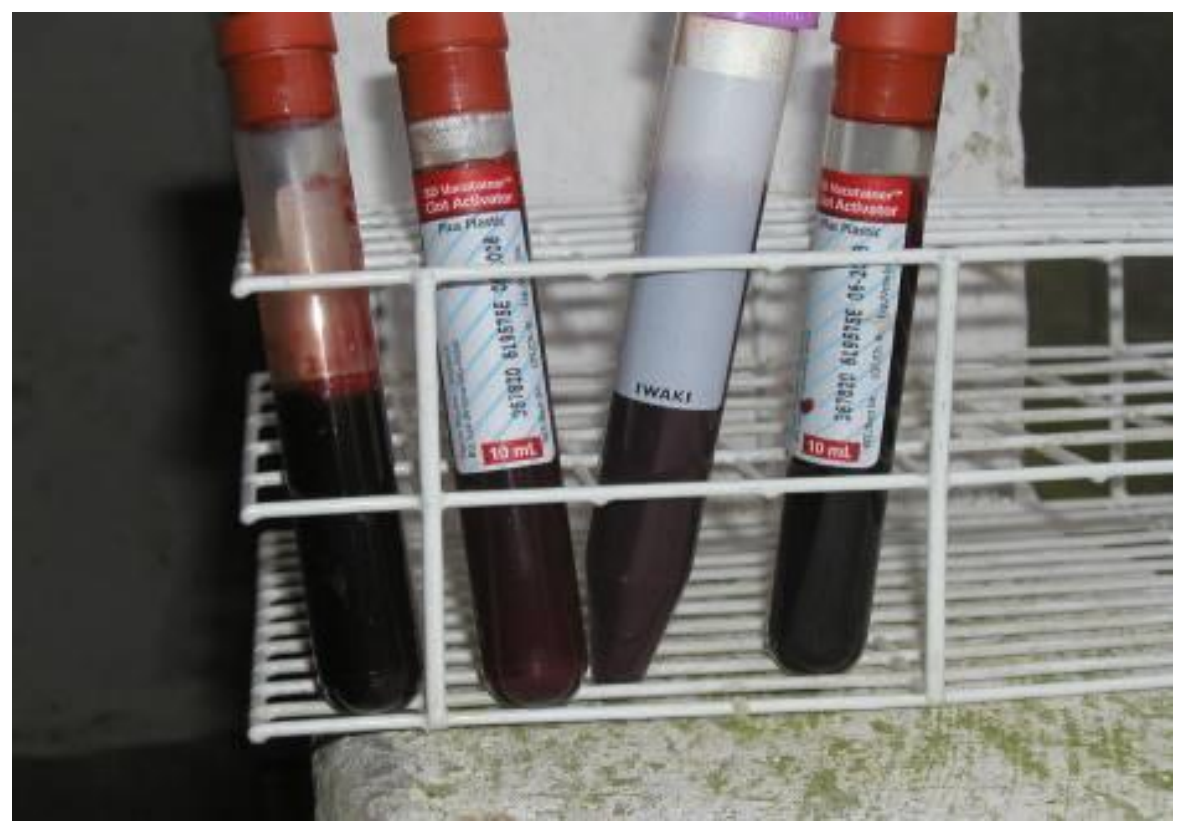

\section{Referências}

CARLE, B. N.; DEWHIRST, JR., W. M. A new method for bleeding swine. Journal of American Veterinarian Medical Association, v. 101, p. 495-6, 1942.

FRAMSTAD, T.; AASS, R.A Blodprøvetaking på gris. Norsk Veterinærtidsskrift, v. 100, n.4, p. 265-272, 1988.

HOERLEIN, A. B.; HUBBARD, E. D.; GETTY, R. The procurement and handling of swine blood samples on the farm. Journal of American Veterinarian Medical Association, v. 128, 357-362, 1951.

POND, W. G.; HOUPT, K. A. Biologia del cerdo. Editora Acribia $2^{\mathrm{a}}$ ed. Zaragoza, 1981, 334p.

POPESKO, P. Atlas of topographical anatomy of the domestic animals. WB Saunders, $2^{\mathrm{a}}$ ed. Philadelphia ,1983, 870p.

SOBESTIANSKY, J.; BARCELLOS, D.; MORES, N.; CARVALHO, L. F.; OLIVEIRA, S. Clínica e patologia suína. 2 ed. Goiânia: Universidade Federal de Goiás, 1999. 464p. 